\title{
The Design of a Supporting Device for Badminton Footwork Practice Based on Microcontroller Technology
}

\author{
Ngadiman Ngadiman*, Indra Jati Kusuma \\ Department of Physical Education, Health and Recreation \\ Universitas Jenderal Soedirman \\ Purwokerto, Indonesia \\ *ngadiman.unsoed@yahoo.com
}

\author{
Aziz Wishnu Widhi Nugraha \\ Department of Electronic Engineering \\ Universitas Jenderal Soedirman \\ Purwokerto, Indonesia \\ asw_te@yahoo.com
}

\begin{abstract}
This research was aimed at designing a supporting device for Badminton footwork practice based on Microcontroller Technology. The method used was the method of Development consisted of several designing stages, starting from product design, design validation, design improvement, design making, product trial, product revision, and utilization trial. The result showed that this device might become the coach supporting device to guide the athletes during the footwork practice. This device might locate the target to reach by an athlete in one particular time through the display light. The device might be manually or automatically operated and function as a measuring device for an athlete's achievement level in meeting the target during exercise. This device might measure an athlete's achievement level in performing each set of practice and be adjusted with the difficulty level based on required needs. The practice difficulty level in this device might be integrated and various based on the time practice parameter, number of footsteps in each set of practice, or foot-distance parameter through the target sensor located in the field. The validity test was conducted by the experts. This research concludes that the design of this device might be utilized to well support the Badminton footwork practice.
\end{abstract}

\section{Keywords: design, footwork, microcontroller}

\section{INTRODUCTION}

In this recent era, sport has become a necessity of a nation's life. The nation's achievement reflects the capacity of a nation in the other fields. A nation with a fast developing knowledge and technology tends to have a sophisticated sports development. The best athletes' achievements in the developed countries, making the world records, may not be separated from the involvement of knowledge, technology and engineering [1]. The development of sports device and engineering is greatly required to keep up with the coaching and organizing technology of a sport activity. To evaluate the sports technological influence, the concept of performance index was developed for athletes to improve their performance as the higher the index, the higher the sports development [2].

Badminton is the fastest racket game with enormous changes in its games as its speed patterns. Technological innovation has provided great changes in badminton games.
Technology has changed the game standards due to the recent implementation of technology and new materials related to its development of devices, such as referee, racket, shoes, and clothes. Badminton games have recently been oriented on skills and technology. Video is one most important technology to improve the skill techniques. Thus, technology in badminton games has been widely developed [3].

In badminton games, there are some basic practice techniques to well master, such as racket holding, shuttle cock hitting, and footwork controlling techniques. To train the badminton athletes' footwork performance, there are some practical methods, such as shadowing practice [4]. The commonly used footwork practice method instructed by the badminton coaches is through a traditional approach, that is, by directly instructing the badminton players while immediately pointing the desired field points to reach. This practice technique has proven having some weak points, such as inconsistent given tempo instructions, highly dependence on the coaches' physical and mental conditions, not well arranged practice time to meet the needs boredom no independent exercises, easily predicted movement directions, and highly influencing coaches' characters. If these practices last longer, the athletes' physical conditions and the coaches' concentration may drop that the coaches may not optimally evaluate the athletes' footwork as their concentration mainly emphasizes on the instructions given.

Due to the commonly implemented (traditional) footwork practice weaknesses, especially there is no objective indicator to figure out the exercise result progress, it is necessary to design a supporting device for the athletes' footwork exercises based on microcontroller technology. It is expected that by using this supporting device, the practice intensity and model may be well organized to meet the needs and the practice objective achievement indicator may also be well obtained.

\section{METHOD}

This research design was commonly known as R\&D (Research and Development) due to its final objective to produce a certain supporting device for the badminton athletes' footwork practices based on microcontroller technology. The 


\section{F. Display Lamp}

research method consisted of several designing stages: product design, design validity, design improvement, design making, product trial, product revision, and utilization trial $[5,6]$.

\section{RESULTS AND DISCUSSION}

The design of this supporting device for the badminton athletes' footwork practices was based on microcontroller technology with six main components:

\section{A. Mainboard}

Main board is the device brain functioning to organize all device performances. The picture shows a series of board equipped with some sockets connecting the main board to the other components. The function of each socket should be carefully noticed. The sockets are serially installed on an aluminium bar from the right to the left consisting of socket for laser, handy, sensor, and output. Besides, the other socket located at the back of the main board has the function as the power supply input from adaptor.

\section{B. Adaptor}

Adaptor has the function to provide the electrical power supply to the whole parts of this device. This adaptor has four cables to be connected to the main board through the installed socket at the back of the main board. The installation procedures will be further explained in the following discussion. The appearance of this adaptor is as follows:

\section{Transmitter}

Transmitter has the function to transmit the laser beam to be easily caught by the receiver. Each transmitter has three lasers transmitting together to the receiver.

\section{Receiver}

Receiver has the function to catch the laser beam from the transmitter. The receiver has 3 photodiode sensors to catch the transmitted laser beam. Beside sockets for cables, there are some other components. First, there are six red lamps as the sensor's indicator lamps. If the second red lamp (seen from the back) is on, it means the RX is working as a sensor which delivers the signal to the mainboard as the second sensor and so forth. To change the sensor position (red lamp on), rotate the black circuit breaker located on the RX box. There are also three green lamps functioning as indicator lamp due to the presence or absence of laser to catch. If the green lamp number 1 (seen from the back) is off, it means that the first photodiode sensor has caught the laser beam from TX and so forth.

\section{E. Handy}

Handy has the function as the device manager based on the provided menu, such as sensor check and manual or automatic mode. Handy has two important parts consisting of LCD and keypad. First, LCD is a screen functioning to show writings representing the operated programs in microcontroller. Second, keypad has the function to input scores or to select menu offered by the device. Its cable socket is located below the handy. Meanwhile, the handy installation procedures and utilization are discussed further.
Display lamp has the function to turn the lamp on showing the field points to reach.

\section{G. Cables}

Cables are the other components functioning to connect one part to the other part centred in the main board. Those cables are explained as follows:

1) Cable from adaptor: The cable from adaptor has only one end. It means that the cable comes out from the adaptor and is unable to be plugged off, while the other end is connected to the mainboard. This is a thin cable consisting of four fibers with different colors.

2) Laser cable (TX): Laser Cable has two ends connecting the laser box (TX) to the main board. This section consists of thin round gray cable with a $\mathrm{CD}$ connector at the cable end.

3) Handy cable: Handy uses a rainbow cable consisting of 18 fibers. This cable uses DB25 connector (connector usually found in old printer). This device has only one cable with DB25 connector that it is quite impossible to be misconnected (exchanged).

4) $R X$ sensor cable: UTP (LAN) cable is commonly used to connect $\mathrm{RX}$ with the main board through the DB9 connector. This device uses two cables utilizing DB9 connector, that is, RX sensor cable and lamp output cable. However, the output cable has a notification stating that the cable is for lamp output. In other words, the cable with DB9 connector without "output" written down is the cable for $\mathrm{R}$ sensor.

5) Lamp output cable: Lamp output cable is similar with that for RX sensor, but there is the word "output" written down on its DB9 head connector.

The design of this supporting device for footwork exercise based on microcontroller technology is divided into two parts: hardware and software design. The system is commonly built with the following functions.

- This device has the function as a supporting device to guide athletes in performing footwork exercise. This device will once display the targeted points to reach by the athletes through the display lamp. This device may be operated in two modes: manual and automatic mode, with the following explanations.

- In manual mode, the coach will manually input the targeted points (locations) to reach by the athletes through the keypad button. This mode principle is basically the same with the footwork practices without any supporting device. The practice difficulty level in this mode is greatly dependent on the coach conditions on particular time. The difficulty level consistency may not be guaranteed in this mode.

- In automatic mode, the coach may just input the practice time and the number of steps to 
guide an athlete to figure out which targeted location to reach

follow in each set of practice. The practice difficulty level may be determined based on the practice time and number of steps to follow in each set of practice. The comparison between time practice and number of steps may determine how fast an athlete should move on each step.

- This device has the function as a measuring device to the achievement made by an athlete to meet the targeted set of practice given by this device both in manual and automatic mode. The success of an athlete to meet the targeted set of practice is determined by the number of correct and incorrect steps made in each set of practice. Step precision is determined by the directions and the targeted points to reach. To know the step precision, some array sensors for the targeted points are greatly required.

To meet the required functions above, this footwork supporting device requires 2 inputs (keypad and sensor array) and 2 outputs (LCD display and targeted location display). Keypad is used to input order and the required parameters. Array sensor is used to figure out whether an athlete has reached the targeted points (locations). LCD display is used to display the required information when performing the footwork practice. Meanwhile, the targeted location display is used to in a particular time.

\section{CONCLUSION}

The developed device may be used as the supporting device for badminton footwork practice. The manual and automatic models were developed to adjust the practice difficulty level for different athletes. The developed device may be utilized to measure the success of footwork practice shown in the number of good and bad steps with the average time of each step made.

\section{REFERENCES}

[1] F.K. Fuss, A. Subic, and S. Ujihashi, The impact of technology on sport II. Journal Sport Technology, CRC Press, 2007.

[2] S.J. Haake, "The impact of technology on sporting performance in Olympic sports," Journal of Sports Sciences, vol. 27, no. 13, pp. 14211431, 2009.

[3] G. Singh, "Technology and badminton," British Journal of Sports Medicine, vol. 44(Suppl 1), 2010.

[4] I. Sugiarto, Total badminton, Solo: CV. Setyaki Eka Anugrah, 2002.

[5] S. Arikunto, Prosedur Penelitian Suatu Pendekatan Praktek [A Research Procedure: A Practical Approach], Jakarta: RinekaCipta, 2002.

[6] S. Hadi, Metodologi Research Jilid 3 [Reseach Methodology, Third Edition], Yogyakarta: Andi Offset, 2002. 